ЛЕЖНИНА Юлия Павловна - кандидат социологических наук, старший научный сотрудник Института социальной политики Национального исследовательского университета «Высшая школа экономики» (101000, Россия, г. Москва, ул. Мясницкая, 20; lezhnina@list.ru); cmapший научный сотрудник Института социологии ФНИСЦ РАН (117218, Россия, г. Москва, ул. Кржижановского, 24/35, корп. 5)

\title{
НА ПОРОГЕ НОВОГО ПРЕЗИДЕНТСКОГО СРОКА В.В. ПУТИНА: ЧЕГО ОЖИДАЕТ НАСЕЛЕНИЕ?
}

Аннотация. Поддержка государственных социальных инициатив населением на микроуровне зачастую зависит от того, насколько они соответствуют представлениям о приоритетах социальной политики самих граждан. В этой связи соотнесение государственных программ и мероприятий с запросом россиян способно обеспечить их легитимность и общее принятие населением.

В статье на данных общероссийского исследования ИС ФНИСЦ РАН 2018 г. показано, что россияне предьявляют запрос на активное участие государства в обеспечении собственного благополучия, Т.к. в значительной мере не имеют возможности решать свои проблемы за счет собственных экономических ресурсов и социальных сетей. При этом повестка дня, озвученная в послании Президента РФ Федеральному собранию в 2018 г., в целом поддерживаемая населением, отвечает не самым актуальным для него вызовам в социальной сфере.

Ключевые слова: социальная политика, социальный запрос, социальные ожидания, государственное управление

И зучение ожиданий населения от государственной политики, безусловно, представляет практический интерес, т.к. дает возможность определить повестку социальной политики в максимальном соответствии запросам населения, что положительно сказывается на ее общем восприятии. В этой связи не удивительно, что и в рамках академических исследований этот вопрос также нашел свое отражение. Заметный толчок в развитии данной проблематики был сопряжен со становлением так называемых государств всеобщего благосостояния на территории развитых стран. При этом их кризис, который определяет повестку соответствующего предметного пространства сегодня, только подстегивает интерес к изучению запроса населения на социальную политику, т.к. позволяет обнаружить, а соответственно смягчить зоны максимальной напряженности.

Стоит отметить, что в целом жители европейских стран предъявляют запрос на достаточно активную социальную поддержку со стороны государства [Williams, Hill, Davies 1999], однако ее масштаб и приоритеты могут отличаться от страны к стране. Значительная доля работ по соответствующим аспектам посвящена анализу дифференциации запроса населения (и установок во взаимоотношениях с государством в целом) в зависимости от особенностей социальной политики [Gelissen 2002; Gundelach 1994; Bean, Papadakis 1993; Peillon 1996; Svallfors 1997; 2003; Blekesaune, Quadagno 2003]. При этом изученность ожиданий в этой сфере у населения посткоммунистических стран не так глубока даже при наличии целого ряда исследований [Mason, Kluegel, Wegener 1995; Domanski, Heyns 1995; Mason 1995; McDonough 1995; Salmina 2014].

Запрос россиян на социальную политику, несмотря на активное изучение отношения населения к тем или иным государственным инициативам, описывают опять же лишь отдельные работы [Социальные неравенства... 2008; Авраамова 2006]. Согласно им население страны ориентировано на ключе- 
вую роль государства в реализации социальной политики, но мнения о том, в какой форме (прямых трансфертов или посредством создания институтов) она должна осуществляться, несколько дифференцированы. Более того, именно с этим отчасти и связаны различия представлений об инструментах социальной политики у представителей различных социальных групп.

Российское население в целом, несмотря на стереотипы относительно его патернализма, в значительной степени ориентируется на достижение своих целей собственными силами. Однако жизненные обстоятельства и объективные причины способны расшатывать положение россиян и выводить на относительно высокий уровень их ожидания от государства, близких и родственников, локальных сообществ при решении возникающих проблем. Кризисные процессы последних лет и общее проседание положения населения только способствовали усилению запроса россиян на участие государства в жизни граждан к новому президентскому сроку В.В. Путина. Поэтому не удивительно, что 52\% россиян считают, что без поддержки со стороны государства им и их семьям не выжить, и только $48 \%$ из них говорят, что смогут сами обеспечить себя и свою семью и не нуждаются в государственной поддержке 1 . При этом в 2014 г. это соотношение было равно $60 \%$ и $40 \%$ соответственно, а в $2006-65 \%$ и $35 \%$. Это означает, что за последнее десятилетие потребность населения в поддержке государства только возросла, что не удивительно, т.К. за этот период страна прошла через два крупных экономических кризиса. В целом об отсутствии необходимости в помощи со стороны государства говорят только $17 \%$ россиян (см. рис. 1), т.е. запрос на государственную социальную политику выражен ярко.

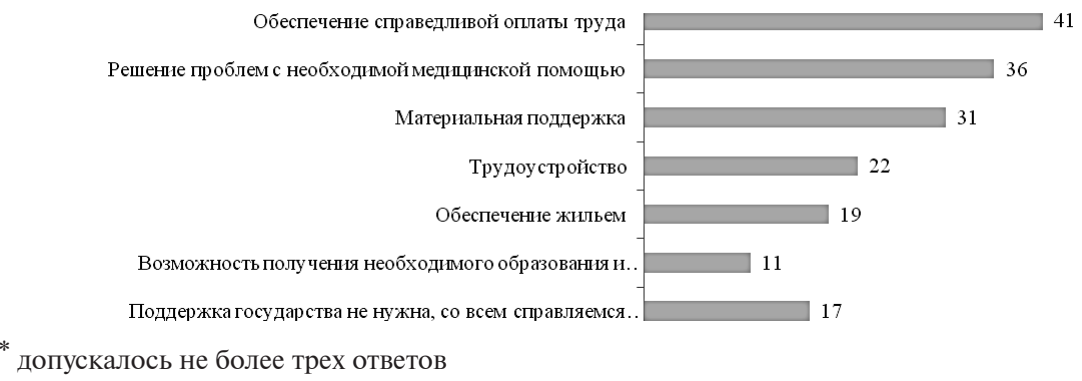

Рисунок 1. Проблемы, в решении которых россиянам и их семьям в наибольшей степени требуется государственная поддержка и содействие, 2018 г., \%

Если же говорить о структуре основных потребностей населения в вопросе государственной социальной поддержки, то в наибольшей степени ему необходимо содействие в таких вопросах, как обеспечение справедливой оплаты труда $(41 \%)$ и решение проблем с необходимой медицинской помощью (36\%). В остальных вопросах - материальной поддержки (31\%), трудоустройства (22\%), обеспечения жильем (19\%), получения необходимого образования (11\%) -

\footnotetext{
${ }^{1}$ В статье использованы базы мониторингового исследования Института социологии ФНИСЦ РАН «Динамика социальной трансформации современной России в социально-экономическом, политическом, социокультурном и этнорелигиозном контекстах», созданные при финансовой поддержке РНФ (8-я волна, проведенная в апреле 2017 г.). Выборка составляла 4000 респондентов, репрезентирующих взрослое население страны в возрасте 18 лет и старше по основным социально-демографическим показателям. Подробнее о выборке этого исследования см. [Российское общество... 2017].
} 
Таблица 1

Наличие ресурса реальной поддержки со стороны знакомых, друзей или родственников при решении проблем, 2015-2018, \%*

\begin{tabular}{|l|c|c|}
\hline \multicolumn{1}{|c|}{ Ресурсы поддержки } & $\mathbf{2 0 1 5}$ & $\mathbf{2 0 1 8}$ \\
\hline Возможность взять в долг до 100 тыс. руб. & 32 & 25 \\
\hline Поиск приработков & 27 & 15 \\
\hline Обращение к хорошим врачам, устройство в хорошую больницу & 22 & 13 \\
\hline Устройство на хорошую работу & 12 & 8 \\
\hline Возможность взять в долг более 100 тыс. руб. & 5 & 6 \\
\hline Устройство детей в хорошую школу & 8 & 5 \\
\hline Решение жилищной проблемы & 5 & 4 \\
\hline $\begin{array}{l}\text { Содействие в доступе к должностным лицам, способным помочь в } \\
\text { решении проблем }\end{array}$ & 5 & 4 \\
\hline Поступление в хороший вуз & 5 & 3 \\
\hline Продвижение по карьерной лестнице & 4 & 2 \\
\hline Таких знакомых нет & $24^{* *}$ & 51 \\
\hline
\end{tabular}

* Упорядочено по 2018 г., допускалось любое число ответов.

** В 2015 г. этот вариант ответа формулировался как «Затрудняюсь ответить».

помощь государства требуется менее чем в трети случаев. Таким образом, наиболее распространенные текущие запросы населения сопряжены с созданием институциональных и инфраструктурных возможностей решать возникающие проблемы. При этом особой остротой отличаются вопросы, связанные с системой здравоохранения.

Стоит отметить, что собственные ресурсы для купирования возникающих проблем у россиян достаточно ограничены. О том, что не имеют тех или иных проблем ${ }^{1}$ и живут нормально, говорят 17\% населения, в то время как в 2006 г. этот показатель был равен $11 \%$. Однако доля тех, кто сталкивается с материальными проблемами, относительно стабильна (39\% и $40 \%$ в эти годы соответственно). При этом значительно снизилось число россиян, отмечавших отсутствие социальных гарантий на случай старости, безработицы, инвалидности (изменение с $21 \%$ до $8 \%$ ). В этой связи можно говорить о том, что вопрос улучшения собственного материального положения актуален для массовых слоев населения страны. О том, что не предпринимают ничего для этого, т.к. нет необходимости, в 2018 г. говорят 17\%, что практически в 3 раза меньше, чем в 2006 г. (6\%). Однако наряду с этим заметно увеличивается доля россиян, которые ничего не предпринимают для улучшения собственного положения, потому что ничего не могут сделать: за последние 12 лет она выросла с $13 \%$ до $20 \%$. Так что, несмотря на локальные улучшения, общий запрос на поддержку государства со стороны россиян растет в связи с сокращением ресурса их собственного влияния на ситуацию.

1 В рамках опроса предусматривалась возможность отметить наличие 18 типов проблем (плохое материальное положение, проблемы с питанием, одеждой или обувью, жильем, работой, изменение общественного положения в последние годы, здоровье членов семьи, семей с детьми, невозможность получить образование, отсутствие времени, внимания со стороны других людей, возможности общения с родственниками и друзьями, возможности качественного проведения досуга, вредные привычки [алкоголизм, наркомания и т.п.] у членов семьи, незащищенность от насилия, одиночество) и внести собственный вариант ответа. 
При этом более половины (51\%) населения имеют крайне ограниченный ресурс помощи и со стороны социальных сетей и говорят, что их знакомые и родные не способны помочь в решении таких проблем, как поиск приработков, обращение к врачам, устройство на работу и т.д. (см. табл. 1). Даже такой ресурс, как возможность взять в долг сумму до 100 тыс. руб., доступен только четверти россиян.

При этом за последние 3 года объем ресурсов социальных сетей у россиян только сократился. Возможности решать через них проблемы снизились в 1,31,8 раза, потенциал использования знакомств для обращения к хорошим врачам и устройства в хорошую больницу сократился в 1,7 раза. Таким образом, ни собственные экономические активы, ни социальный капитал не могут выступать сегодня для населения страны «страховкой», покрывающей несовершенства государственной системы социальной поддержки.

В этих условиях модель социальной политики, на которую формируется запрос со стороны населения, определяется через активное участие государства в решении социальных проблем: $41 \%$ россиян отмечают, что государство должно защищать всех малоимущих, и еще $39 \%$ - что от государства требуется оказание адресной помощи и некоторым другим социальным группам, попавшим в трудное положение (безработным, бедным семьям с детьми и т.д.). О минимизации роли государства в том или ином виде говорят только $20 \%$ населения (см. рис. 2), при этом 13\% из них допускают выполнение им исключительно его гуманитарной функции, когда государство должно обеспечивать только нетрудоспособных (престарелых, инвалидов, сирот). Также в пользу усиления вмешательства властей в жизнь общества для поддержания всеобеего благосостояния через социальную политику как систему перераспределения ресурсов выступает о тот факт, что, по мнению россиян $(54 \%)$, надо проявлять гуманность и те, кто материально преуспел, должны помогать тем, кто не так успешен, и заботиться о них, только $46 \%$ считают, что материальных успехов люди должны добиваться сами, а те, кто этого не хочет, пусть живут бедно - это справедливо. То есть, в настоящий момент роль государства в социальной сфере в представлениях россиян крайне высока, а понятие социальной поддержки носит расширенную трактовку.

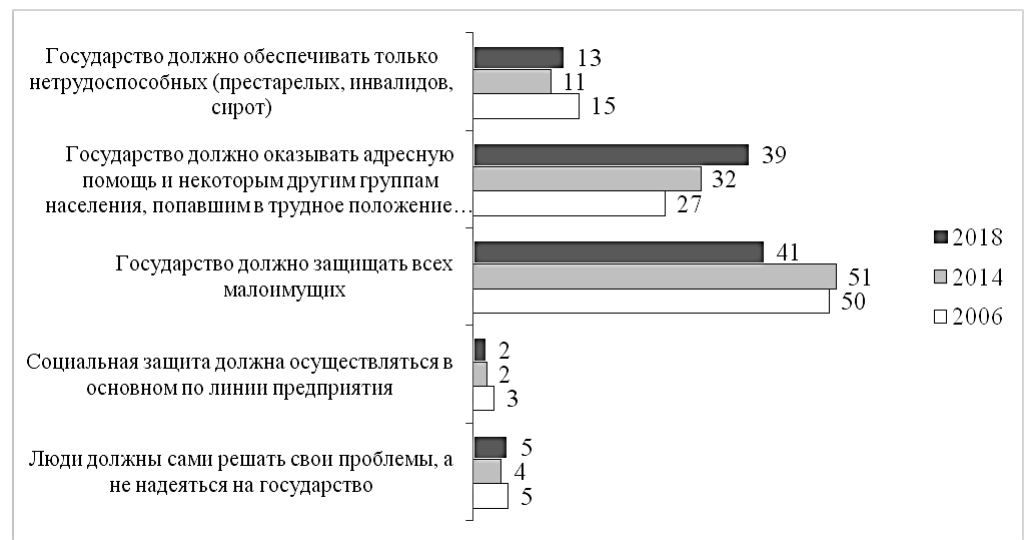

Рисунок 2. Желаемые принципы построения системы социальной защиты граждан, 2006-2018 г., \%

Стоит отметить, что за последние 12 лет предпочтения россиян относительно модели социальной политики несколько изменились. Около $80 \%$ населения 
как в 2006, так и в 2014 и 2018 гг. склонялись к расширенному видению состава социально незащищенных слоев: в их число включались такие группы, как люди, попавшие в трудное положение, безработные, бедные семьи с детьми и т.д., а также все малоимущие. Однако за этот период происходило «перетекание» сторонников формирования максимально развернутого списка получателей социальной поддержки к умеренно развернутому: доля тех, кто говорил о помощи всем малоимущим сократилась с 50\% до 41\%, а доля тех, кто говорил об адресной помощи попавшим в трудное положение, увеличилась с $27 \%$ до $39 \%$ (см. рис. 2). Это является свидетельством того, что россияне начинают более ответственно подходить к вопросу определения спектра получателей социальных трансфертов, что стало реакцией на ощущение ограниченности ресурсов государственной поддержки.

Запрос россиян на вмешательство государства намного шире, чем просто потребность в социальной защите. Так, например, более $90 \%$ населения (см. табл. 2) говорят о том, что государство всегда должно обеспечивать достойный уровень жизни пожилым (98\%), медицинскую помощь всем нуждающимся (97\%), справедливую оплату труда (96\%) и равенство возможностей для детей из семей с разным достатком $(92 \%)$, т.е. первоочередные функции государства в их представлении - обеспечение базовых гуманитарных гарантий (с отдельным вниманием к сфере здравоохранения) и институциональных рамок функционирования социально-экономической системы. Более $80 \%$ россиян также предъявляют запрос на обеспечение возможностей получения образования (89\%), жилья (88\%), работы по специальности (87\%), прожиточного минимума безработным $(82 \%)$ и сокращение разницы в доходах между бедными и богатыми (82\%). Такой расширенный набор запросов населения по отношению к государству является отражением ощущения общей уязвимости россиян.

Таблица 2

\section{Обязанности государства по отношению к населению в представлениях россиян, 2018 г., \%}

\begin{tabular}{|l|c|c|}
\hline \multicolumn{1}{|c|}{ Обязанности государства } & Да & Нет \\
\hline $\begin{array}{l}\text { Обеспечивать нормальный уровень жизни в старости людям, честно } \\
\text { отработавшим свое }\end{array}$ & 98 & 2 \\
\hline Обеспечивать медицинской помощью всех, кто в ней нуждается & 97 & 3 \\
\hline Обеспечивать справедливую оплату труда всех работающих & 96 & 5 \\
\hline $\begin{array}{l}\text { Обеспечивать равенство возможностей для детей из семей с разным } \\
\text { достатком }\end{array}$ & 92 & 8 \\
\hline $\begin{array}{l}\text { Обеспечивать получение необходимого образования всем, кому это } \\
\text { нужно }\end{array}$ & 89 & 11 \\
\hline $\begin{array}{l}\text { Обеспечивать минимально необходимым жильем тех, кто сам не в } \\
\text { состоянии это сделать }\end{array}$ & 88 & 12 \\
\hline $\begin{array}{l}\text { Обеспечивать работой по специальности каждого, кто хочет } \\
\text { работать }\end{array}$ & 87 & 13 \\
\hline Обеспечивать прожиточный минимум безработным & 82 & 18 \\
\hline Сокращать разницу в доходах между бедными и богатыми & 82 & 18 \\
\hline Обеспечивать уход за детьми работающих родителей & 81 & 19 \\
\hline $\begin{array}{l}\text { Выплачивать всем ежемесячно определенную сумму денег в } \\
\text { качестве ренты от природных богатств страны }\end{array}$ & 79 & 21 \\
\hline
\end{tabular}


Стоит отметить, что ключевым субъектом социальной политики и решения социальных проблем, по мнению населения, является не просто государство, а федеральный центр. Его ответственность за обеспечение практически любых общественных благ - от благоприятной экологии до достойного положения пенсионеров - в представлениях россиян выше, чем у других субъектов (см. табл. 3). Региональные власти, по их мнению, должны вносить меньший, но весомый вклад в решение таких проблем, как обеспечение жильем (20\%) и поддержание благоприятной экологической обстановки $(30 \%)$, разделяя в этих вопросах ответственность с местными властями (20\% и $23 \%$ соответственно). При этом от местных властей россияне ожидают активного участия в помощи семье и детям (23\%), включая обеспечение детскими дошкольными учреждениями (33\%). Работодатели в их представлениях обязаны гарантировать справедливую оплату труда (37\%) и обеспечение рабочего места (24\%). При этом сами россияне до определенной степени готовы нести ответственность за личную безопасность (23\%) и получение высшего образования $(22 \%)$.

Таблица 3

Распределение ответственности за решение различных проблем, 2018, \%

\begin{tabular}{|c|c|c|c|c|c|c|}
\hline Перечень проблем & 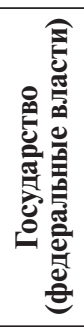 & 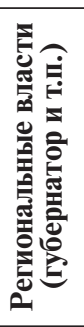 & 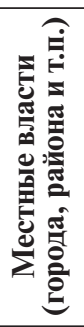 & 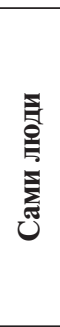 & 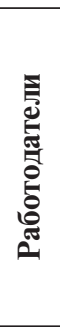 & 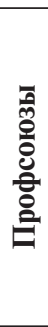 \\
\hline Пенсионное обеспечение & 87 & 7 & 3 & 1 & 1 & 1 \\
\hline Борьба с бедностью & 77 & 12 & 7 & 3 & 1 & 1 \\
\hline $\begin{array}{l}\text { Справедливое распределение } \\
\text { материальных благ }\end{array}$ & 75 & 11 & 7 & 4 & 2 & 1 \\
\hline Медицинская помощь & 70 & 16 & 12 & 2 & 0 & 0 \\
\hline $\begin{array}{l}\text { Возможность получения } \\
\text { среднего образования }\end{array}$ & 63 & 10 & 13 & 14 & 0 & 0 \\
\hline $\begin{array}{l}\text { Возможность получения } \\
\text { высшего образования }\end{array}$ & 58 & 12 & 7 & 22 & 1 & 0 \\
\hline Помощь семье и детям & 49 & 18 & 23 & 8 & 1 & 2 \\
\hline Личная безопасность & 46 & 9 & 21 & 23 & 1 & 0 \\
\hline Обеспечение жильем & 46 & 20 & 20 & 12 & 1 & 1 \\
\hline Справедливая оплата труда & 45 & 10 & 6 & 1 & 37 & 2 \\
\hline $\begin{array}{l}\text { Обеспечение детскими } \\
\text { дошкольными учреждениями }\end{array}$ & 41 & 25 & 33 & 1 & 1 & 1 \\
\hline $\begin{array}{l}\text { Благоприятная экологическая } \\
\text { обстановка }\end{array}$ & 39 & 30 & 23 & 8 & 1 & 0 \\
\hline Обеспечение рабочих мест & 37 & 15 & 17 & 5 & 24 & 1 \\
\hline
\end{tabular}

При этом эффективность государства в решении социальных проблем, за которые население возлагает на него ответственность, остается достаточно низ- 
кой. Так, изменение положения дел за последние 5 лет в различных секторах социальной сферы россияне чаще оценивают как ухудшение, чем улучшение. Исключением является только ситуация с дошкольными детскими учреждениями, динамика в которой вызывает позитивную реакцию практически в 2 раза чаще, чем негативную. Отрицательная оценка изменений доминирует над положительной и при рассмотрении состояния экономики страны в целом, а также среднего и высшего образования; для жилищной и пенсионной сфер, а также возможностей зарабатывать соответствующая разница превышает 2 раза, а для системы здравоохранения $-4,5$ раза (см. табл. 4).

Таблица 4

Оценка динамики ситуации в различных сферах жизни российского общества за последние 5 лет, 2018 г., \%

\begin{tabular}{|l|c|c|c|}
\hline \multicolumn{1}{|c|}{ Сферы жизни } & Улучшилось & Не изменилось & Ухудшилось \\
\hline Дошкольные детские учреждения & 29 & 54 & 17 \\
\hline Состояние экономики страны в целом & 26 & 40 & 34 \\
\hline Среднее образование & 15 & 60 & 25 \\
\hline Высшее образование & 14 & 59 & 27 \\
\hline Жилищная ситуация & 15 & 54 & 31 \\
\hline Пенсионное обеспечение & 14 & 54 & 32 \\
\hline Возможность зарабатывать & 16 & 47 & 37 \\
\hline Здравоохранение & 11 & 42 & 47 \\
\hline
\end{tabular}

В целом ситуация с системой здравоохранения - одна из самых напряженных в социальной сфере. Ухудшение медицинского обслуживания (и образования) не беспокоит только $12 \%$ россиян, более половины из них испытывают по этому поводу или сильную тревогу (39\%) или постоянный страх (15\%). Эти опасения небезосновательны, ведь уже сейчас заметной части населения приходится использовать платные медицинские услуги (44\% за последние 3 года перед опросом), и более чем в половине случаев (57\%) это связано с отсутствием их бесплатных аналогов.

С учетом сложившейся ситуации задача создания доступной и качественной медицинской помощи, которая вошла в ежегодное послание президента РФ В. Путина в 2018 г., в максимальной степени соответствует запросу населения. Впрочем, важными для большинства россиян являются и остальные пункты повестки (см. табл. 5) - от приведения в порядок дорог до увеличения продолжительности жизни. Неважными хотя бы для $10 \%$ населения можно назвать лишь развитие ипотеки, формирование среднего класса и достижение устойчивого роста населения страны. В целом, несмотря на значимость обозначенных в послании президента 2018 г. задач, оно обрисовывает контуры ближайшего развития социальной сфере радужнее, чем оно видится населению страны. В повседневности россияне сталкиваются с проблемами более насущного характера, чем основная часть вопросов президентской повестки: например, они ожидают справедливой оплаты труда, а не роста реальных доходов и формирования массового среднего класса.

Большинство из поставленных президентом задач, несмотря на их важность, видятся населению труднореализуемыми. Так, возможность увеличения про- 
должительности жизни россиян до 80 лет в перспективе до 10-15 лет положительно оценивают менее половины населения (45\%). Такие задачи, как приведение в порядок региональных и местных дорог, рост реальных доходов работающего населения, увеличение размеров пенсий, их индексация выше темпов инфляции, создание современной инфраструктуры в сельской местности, формирование равных образовательных возможностей относительно чаще оценивались как нереализуемые за 15 лет, о чем говорят 36-46\% россиян. Однако в горизонте до 10-15 лет на их решение рассчитывают большинство россиян (см. табл. 5). Самые быстрые эффекты ожидаются в вопросе появления доступной (до 7\%) для большинства российских граждан и их семей ипотеки - соответствующую перспективу в ближайшие 5-6 лет видят более трети (34\%) населения страны.

Таблица 5

\section{Оценка россиянами реалистичности задач, поставленных в послании президента} РФ В. Путина Федеральному собранию в 2018 г., 2018, \%

\begin{tabular}{|c|c|c|c|c|}
\hline \multirow[b]{2}{*}{ Задачи } & \multirow{2}{*}{$\begin{array}{c}\text { Реализация } \\
\text { этой задачи } \\
\text { для меня не } \\
\text { важна }\end{array}$} & \multicolumn{3}{|c|}{$\begin{array}{c}\text { Это важная задача, и она будет } \\
\text { реализована: }\end{array}$} \\
\hline & & $\left|\begin{array}{c}\text { в } \\
\text { ближайшие } \\
5-6 \text { лет }\end{array}\right|$ & $\begin{array}{l}\text { в течение } \\
10-15 \text { лет }\end{array}$ & $\begin{array}{c}\text { вряд ли } \\
\text { будет } \\
\text { реализована }\end{array}$ \\
\hline $\begin{array}{l}\text { Создание доступной и качественной } \\
\text { медицинской помощи }\end{array}$ & 1,8 & 22,7 & 38,4 & 37,1 \\
\hline $\begin{array}{l}\text { Приведение в порядок региональных и } \\
\text { местных дорог }\end{array}$ & 1,8 & 23,2 & 34,4 & 40,6 \\
\hline $\begin{array}{l}\text { Рост реальных доходов работающего } \\
\text { населения }\end{array}$ & 2,3 & 26,6 & 34,4 & 36,7 \\
\hline $\begin{array}{l}\text { Увеличение размеров пенсий, их } \\
\text { индексация выше темпов инфляции }\end{array}$ & 3,6 & 27,3 & 30,8 & 38,3 \\
\hline $\begin{array}{l}\text { Создание современной инфраструктуры } \\
\text { в сельской местности }\end{array}$ & 4,8 & 19,0 & 36,8 & 39,4 \\
\hline $\begin{array}{l}\text { Формирование равных образовательных } \\
\text { возможностей }\end{array}$ & 6,4 & 25,7 & 31,9 & 36,0 \\
\hline $\begin{array}{l}\text { Обновление и развитие российских } \\
\text { городов с учетом мнения их жителей }\end{array}$ & 6,8 & 23,5 & 36,0 & 33,7 \\
\hline $\begin{array}{l}\text { Увеличение продолжительности жизни } \\
\text { россиян до } 80 \text { лет }\end{array}$ & 8,9 & 13,1 & 31,6 & 46,4 \\
\hline $\begin{array}{l}\text { Появление доступной ипотеки (со } \\
\text { средней ставкой 7\%) для большинства } \\
\text { российских граждан и их семей }\end{array}$ & 10,4 & 34,1 & 29,6 & 25,9 \\
\hline $\begin{array}{l}\text { Устойчивый рост численности } \\
\text { населения России }\end{array}$ & 12,0 & 25,1 & 38,4 & 24,5 \\
\hline $\begin{array}{l}\text { Формирование в стране массового } \\
\text { среднего класса }\end{array}$ & 15,4 & 20,0 & 33,8 & 30,9 \\
\hline
\end{tabular}

Таким образом, запрос россиян на участие государства в решении социальных проблем крайне высок, что обусловлено не столько иждивенческими настроениями, сколько объективной невозможностью россиян самостоятельно решать возникающие проблемы, связанной с лимитированным доступом к социальной инфраструктуре, плохо функционирующими институтами, нехваткой финансовых ресурсов. При этом постоянное ухудшение состояния социальной сферы 
обусловливает необходимость оперативной реакции государства, в первую очередь федерального центра. Основными пунктами социальной повестки, по мнению населения, выступают реализация гуманитарных функций государства с акцентом на сферу здравоохранения и гарантии институциональных условий, что, безусловно, находит отражение в послании президента 2018 г., но при этом теряется в многообразии иных, менее актуальных для большинства россиян задач этого документа.

Статья подготовлена в рамках проекта ФНИСЦ РАН «Россия и мир: взаимодействие внутренних и внешних факторов развития страны и их отражение в массовом сознании».

\section{Список литературы}

Авраамова Е.М. 2006. О пространстве возможностей реформирования социальной сферы. - Общественные науки и современность. № 3. С. 18-22.

Российское общество и вызовы времени. Книга пятая (под ред. М.К. Горшкова, В.В. Петухова). 2017. М.: Весь Мир. 427 с.

Социальные неравенства и социальная политика в современной России (под ред. М.К. Горшкова, Н.Е. Тихоновой). 2008. ИС РАН. М.: Наука. 423 с.

Bean C., Papadakis E. 1993. Popular Support for the Welfare State: A Comparison between Institutional Regimes. - Journal of Public Policy. Vol. 13. Iss. 3. P. 227-254.

Blekesaune M., Quadagno J. 2003. Public Attitudes toward Welfare State Policies: A Comparative Analysis of 24 Nations. - European Sociological Review. Vol. 19. No. 5. P. 415-427.

Domanski H., Heyns B. 1995. Toward a Theory of the Role of the State in Market Transition: From Bargaining to Markets in Post-Communism. - European Journal of Sociology (Archives Européennes de Sociologie). No. 36. P. 317-351.

Gelissen J. 2002. Worlds of Welfare, Worlds of Consent? Public Opinion on the Welfare State. Leiden, London: Brill. 256 p.

GundelachP. 1994. National Value Differences: Modernization or Institutionalization? - International Journal of Comparative Sociology. Vol. 35. No. 1-2. P. 37-58.

Mason D.S. 1995. Attitudes toward the Market and Political Participation in the Postcommunist States. - Slavic Review. Vol. 54. No. 2. P. 385-406.

Mason D.S., Kluegel J., Wegener B. 1995. Social Justice and Political Change: Public Opinion in Capitalist and Post-Communist States. N.Y.: A. de Gruyter. 359 p.

McDonough P. 1995. Identities, Ideologies and Interests: Democratization and the Culture of Mass Politics in Spain and Eastern Europe. - The Journal of Politics. Vol. 57. No. 3. P. 649-676.

Peillon M. A. 1996. Qualitative Comparative Analysis of Welfare State Legitimacy. Journal of European Social Policy. Vol. 6. No. 3. P. 175-190.

Salmina A. 2014. Social Attitudes towards Welfare Policies in Russia and Other European Countries. - International Social Work. Vol. 57. No. 5. P. 459-469.

Svallfors S. 1997. Worlds of Welfare and Attitudes to Redistribution: A Comparison of Eight Western Nations. - European Sociological Review. Vol. 13. Iss. 3. P. 283-304.

Svallfors S. 2003.Welfare Regimes and Welfare Opinions: A Comparison of Eight Western Countries. - Social Indicators Research. Vol. 64. Iss. 3. P. 495-520.

Williams T., Hill M., Davies R. 1999. Attitudes to the Welfare State and the Response to Reform: A Report of Qualitative and Quantitive Research on Attitudes to the Welfare State and to Proposals for Reform. Great Britain. Dept. of Social Security. Iss. 88. Corporate Document Services. 
LEZHNINA Yulia Pavlovna, Cand.Sci. (Soc.), Senior Researcher at the Institute of Social Policy, National Research University - Higher School of Economics (20 Myasnitskaya St, Moscow, Russia, 101000; lezhnina@list.ru); Senior Researcher at the Sociological Institute - branch of the Federal Center of Theoretical and Applied Sociology, Russian Academy of Sciences (bld. 5, 24/35 Krzhizhanovskogo St, Moscow, Russia, 117218; lezhnina@list.ru)

\section{AT THE BEGINNING OF THE NEW PRESIDENTIAL PERIOD OF V.V. PUTIN: WHAT DO RUSSIANS EXPECT?}

Abstract. The support of state social initiatives by the population at the micro level often depends on their corresponding to the citizens' expectations, including social policy priorities. Relevance of the governmental programs and activities to the Russians' demand ensures their legitimacy and general acceptance by the population.

The article, based on the representative data of the FCTAS RAS survey carried out in 2018 shows that the Russians' request for state participation in solving social problems is extremely high. The main points of the social agenda according to the opinion of the Russians are the development of the humanitarian functions of the state, with an emphasis on healthcare, and guarantees for institutional stability and efficiency. The 2018 President's Message to the Federal Council includes the variety of other issues less relevant for the most Russians. In whole, the Message describes the nearest development of the social sphere in more optimistic terms then population does. In everyday life, the Russians face more pressing problems than those in the presidential agenda.

Keywords: social policy, social request, social expectations, welfare attitudes, public administration 